\title{
Pancreatic islet regeneration through PDX-1/Notch-1/Ngn3 signaling after gastric bypass surgery in $\mathrm{db} / \mathrm{db}$ mice
}

\author{
TAO HUANG, JUN FU, ZHIJING ZHANG, YUHAO ZHANG, YUNJIA LIANG, CUICUI GE and XIANJU QIN \\ Department of General Surgery, Shanghai Eighth People's Hospital, Shanghai 200235, P.R. China
}

Received June 15, 2016; Accepted April 11, 2017

DOI: $10.3892 /$ etm.2017.4896

\begin{abstract}
In view of the compelling anti-diabetic effects of gastric bypass surgery (GBS) in the treatment of morbid obesity, it is important to clarify its enhancing effect on pancreatic islets, which is closely linked with diabetes remission in obese patients, as well as the underlying mechanisms. The present study evaluated the effects of GBS on glycemic control and other pancreatic changes in $\mathrm{db} / \mathrm{db}$ mice. The $\mathrm{db} / \mathrm{db}$ mice were divided into Control, Sham and GBS group. A significant improvement in fasting plasma glucose levels and glucose intolerance were observed post-surgery. At 4 weeks after surgery, further noteworthy changes were observed in the GBS group, including improved islet structure (revealed by immunohistochemical analysis), enhanced insulin secretion, pancreatic hyperplasia and a marked increase in the ratio of $\beta$-cells to non- $\beta$ endocrine cells. Furthermore, notable changes in the levels of Notch-1, pancreatic and duodenal homeobox 1 (PDX-1) and neurogenin 3 (Ngn3) were observed in the GBS group, indicating a potential role of Notch signaling in pancreatic islet regeneration after surgery. In addition, results obtained in PDX-1 knockout (KO), Notch-1 KO and Ngn3 KO mouse models with GBS suggested that elevated PDX-1 resulted in the inhibition of Notch-1, further facilitated Ngn3 and thus promoted pancreatic $\beta$-cell regeneration after GBS. The present findings demonstrated that GBS in $\mathrm{db} / \mathrm{db}$ mice resulted in pancreatic islet regeneration through the PDX-1/Notch-1/Ngn3 signaling pathway, which also reflected the important role of the gastrointestinal system in metabolism control.
\end{abstract}

\section{Introduction}

Type 2 diabetes mellitus (T2DM) is rapidly becoming an epidemic worldwide and patients with T2DM are increasingly diagnosed as being overweight or obese $(1,2)$. Indeed,

Correspondence to: Dr Tao Huang, Department of General Surgery, Shanghai Eighth People's Hospital, 8 Caobao Road, Xuhui, Shanghai 200235, P.R. China

E-mail: gs_huangtao@163.com

Key words: type 2 diabetes mellitus, gastric bypass surgery, pancreatic islet regeneration the increase in the prevalence of obesity is frequently accompanied by an elevation in the number of cases of T2DM. Hyperglycemia is a characteristic included in the clinical manifestation of T2DM. Bariatric surgery is an effective approach to achieve sustained and persistent weight loss for the treatment of morbid obesity $(3,4)$. Given the limitation of drug therapy, novel treatment strategies focusing on surgical treatment are most promising for the control of T2DM. Earlier in the 1980s, a notable improvement in T2DM has been reported after Roux-en-Y gastric bypass (5), and subsequent studies confirmed the marked therapeutic effect of gastric bypass on T2DM (6-8). Animal experiments show that gastric bypass improves the function of pancreatic islets and reduces blood glucose in diabetic mice (9-11). One possibility of achieving substantial decrements in blood glucose after gastric bypass in patients with T2DM is regeneration of pancreatic islets (12), but the specific mechanism underlying the hypoglycemic effect of islet regeneration following gastric bypass treatment has remained to be fully elucidated.

Current knowledge on pancreatic development suggests that Notch signaling is required for early embryonic development and the regulation of cell-fate decisions during organogenesis (13-15). Regeneration of the pancreas has been confirmed to occur through activation of Notch signaling in human chronic pancreatitis (16), as well as during acute pancreatitis in the adult murine pancreas (17). Furthermore, during pancreatic carcinogenesis, the tumor-initiating effect of transforming growth factor- $\alpha$ appears to be mediated via Notch signaling through enlarging a cluster of undifferentiated precursor cells (18). However, to the best of our knowledge, no previous study has assessed the mechanism by which Notch signaling mediates islet regeneration following gastric bypass surgery in patients with T2DM. The db/db mouse model of T2DM exhibits the characteristics of obesity, hyperglycemia and insulin resistance associated with human T2DM and was therefore used in the present study (19-21). To elucidate the possible mechanism underlying diabetes remission after gastric bypass surgery in T2DM patients, the present study analyzed the proteins involved in the Notch signaling pathway as well as regeneration of pancreatic islets following gastric bypass surgery in $\mathrm{db} / \mathrm{db}$ mice.

\section{Materials and methods}

Animals. Twelve-week-old male C57BL/KsJ db/db mice $(\mathrm{n}=45)$ and the gene knockout (PDX-1 KO, Notch-1 KO and 
Ngn3 KO) C57BL/KsJ db/db mice ( $\mathrm{n}=35$ ) (each weighing 40-50 g) were purchased from the National Rodent Laboratory Animal Center (Shanghai, China). Animals were housed in a well-ventilated holding room at a controlled temperature $\left(24^{\circ} \mathrm{C}\right)$ and humidity $(55 \%)$ under a 12 -h light/dark cycle with free access to water and food. The protocol of the present study was approved by the Institutional Research Ethics Committee of Shanghai Eighth People's Hospital (Shanghai, China). Ninety $\mathrm{db} / \mathrm{db}$ mice were randomly divided into three groups: Control group, Sham group (undergoing sham operation) and GBS group (undergoing gastric bypass surgery).

Surgical procedures. Surgeries were performed according to previous protocols (22). In brief, gastric bypass surgery was performed on overnight fasted mice under continuous isoflurane anesthesia. The body of the stomach in mice has a white line indicating the border between the forestomach and glandular stomach. The stomach was carefully divided into two segments by suture along the white line. Special care was taken at the small curve of the stomach to avoid damaging the left and right gastric arteries and vagus nerve, and to ensure that the upper pouch (white pouch) was continuous with the esophagus. A biliopancreatic limb extending $16 \mathrm{~cm}$ from the ligament of Treitz was transected. The distal segment was anastomosed to the gastric remnant and the proximal segment was drained into $12 \mathrm{~cm}$ of the Roux limb by side-to-side anastomosis. For Sham-operated animals, the incision was made at a spot $16 \mathrm{~cm}$ from the ligament of Treitz. The intestine was then reconnected by side-to-side anastomosis, without intestinal rearrangement, and the incision was closed.

Oral glucose tolerance test (OGTT) and measurement of plasma glucose and insulin. For fasting plasma glucose (FPG), blood was collected through cutting the tail tip in conscious animals after fasting overnight. Samples were centrifuged and plasma glucose was analyzed using the glucose oxidase method (Roche/Hitachi 917; Roche Diagnostics, Mannheim, Germany).

For the OGTT, after 12-14 h of fasting, a glucose load ( $2 \mathrm{~g} / \mathrm{kg}$ body weight) was orally administered. Glucose levels were measured in blood obtained by tail bleeding with a glucometer (Roche; Milpitas, CA, USA) at 0, 10, 20, 30, 40, $60,80,100$ and 120 min after glucose administration. For the measurement of insulin, plasma was evaluated using a radioimmunoassay kit (Diagnostics Products Corp., Los Angeles, CA, USA).

Pancreas weight changes and morphological and immunohistochemical analyses. The mice were euthanized at post-operative 4 weeks. Pancreases were carefully excised, weighed, fixed in $4 \%$ paraformaldehyde for $4 \mathrm{~h}$ at room temperature, washed, transferred to cassettes and positioned in the same manner. The fixed tissues were dehydrated in ethanol, cleared in xylene and then embedded in paraffin blocks. Sections $(5 \mu \mathrm{m})$ were cut sequentially, mounted on polylysine-coated slides, rehydrated and subjected to insulin immunohistochemical staining to observe the histopathological changes. The slides were microwaved for antigen retrieval, and treated for blocking the endogenous peroxidase activity as described previously (23). The slides were incubated with insulin antibody (12018; 1:1,000 dilution; Sigma-Aldrich; Merck KGaA, Darmstadt, Germany) overnight at $4^{\circ} \mathrm{C}$, then incubated with FITC-conjugated anti-mouse IgG (F9137; 1:100 dilution; Sigma-Aldrich; Merck KGaA) secondary antibody for $1.5 \mathrm{~h}$ at room temperature. The slides were covered with DAPI mounting medium or an aqueous mounting solution.

For determination of the $\beta$-cell/non- $\beta$ endocrine cell ratio, 10 sections (at least $200 \mu \mathrm{m}$ apart) were immunostained for insulin and counterstained with DAPI. Sections were examined using a confocal microscope (A1; Nikon, Tokyo, Japan) connected to a computer with NIS elements v4.3 software (Nikon). Images (magnification, $\mathrm{x} 4$; spanning the entire tissue for each slide) were acquired using an X-Y motorized microscope with resolution sufficient to identify single $\beta$-cells, and 'stitched together' using the MetaMorph software program (v.7; Molecular Devices, Sunnyvale, CA, USA). Insulin staining in each section was calculated by MetaMorph software and then checked manually to remove irrelevant spots or to add $\beta$-cells that stained weakly. MetaMorph-quantified total tissue area (based on measurement of DAPI-stained area) and insulin-positive area (based on measurement of glucagon/somatostatin/c-peptide cocktail-positive area) to generate $\beta$-cell/non- $\beta$ endocrine cell ratio.

Western blot analysis. Western blotting was performed as described previously (24), with certain modifications. Total protein was extracted from pancreatic tissues and measured with the Bio-Rad Protein Assay Kit (Bio-Rad Laboratories, Inc., Hercules, CA, USA). Protein $(20 \mu \mathrm{g})$ was separated by $10 \%$ SDS-PAGE and transferred to polyvinylidene difluoride membranes (Merck KGaA, Darmstadt, Germany). After blocking for $1 \mathrm{~h}$ with 5\% non-fat dry milk in PBS, membranes were incubated with specific primary antibodies including Notch1 (sc-71719; 1:1,000), pancreatic and duodenal homeobox 1 (PDX-1) (sc-390792; 1:800), neurogenin 3 (Ngn3) (sc-13793; 1:100) (Santa Cruz Biotechnology, Inc., Dallas, TX, USA) overnight at $4^{\circ} \mathrm{C}$, then incubated with goat anti-rabbit horseradish peroxidase (HRP)-coupled secondary (sc-2030; 1:1,000; Santa Cruz Biotechnology, Inc.) for $1.5 \mathrm{~h}$ at room temperature and detected by chemiluminescence (Thermo Fisher Scientific, Inc., Waltham, MA, USA). $\beta$-actin was used as a protein loading control.

$R N A$ isolation and reverse-transcription quantitative polymerase chain reaction ( $R T-q P C R)$. RT-qPCR was performed as previously described (25), with certain alterations. In brief, total RNA was extracted from cells with TRIzol reagent (Thermo Fisher Scientific, Inc.) and refined using an RNeasy Mini kit (Qiagen, Valencia, CA, USA) in accordance with the manufacturer's protocol. Samples $(1 \mu \mathrm{g}$ RNA) were reverse-transcribed to cDNA in a first-strand cDNA synthesis reaction with PrimeScript RT-PCR kit (Takara Biotechnology Co., Ltd., Dalian, China), at $37^{\circ} \mathrm{C}$ for $25 \mathrm{~min}$, then incubated at $85^{\circ} \mathrm{C}$ for $5 \mathrm{sec}$ in $20 \mu \mathrm{l}$ of reaction volume. Synthesized cDNA was amplified by real-time PCR in a Chromo 4 instrument (Bio-Rad Laboratories, Inc.) using the SsoFast ${ }^{\mathrm{TM}}$ EvaGreen Supermix (Bio-Rad Laboratories, Inc.) and then analyzed with Opticon Monitor Analysis 2.0 Software (Bio-Rad Laboratories, Inc.). Specificity was determined by electrophoretic analysis 


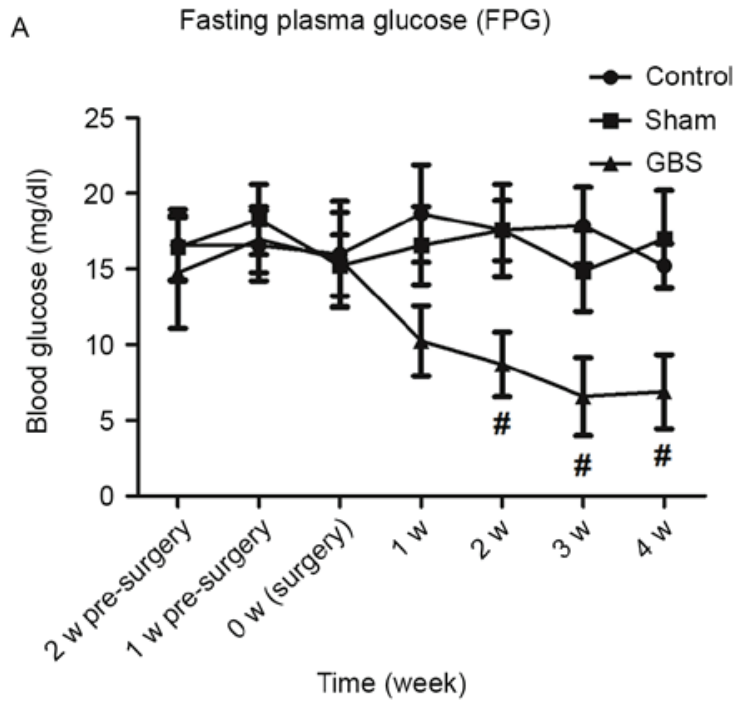

C

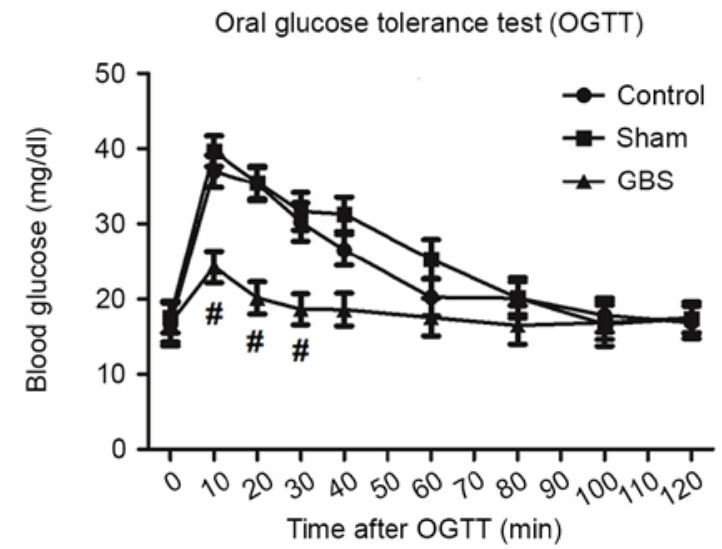

B

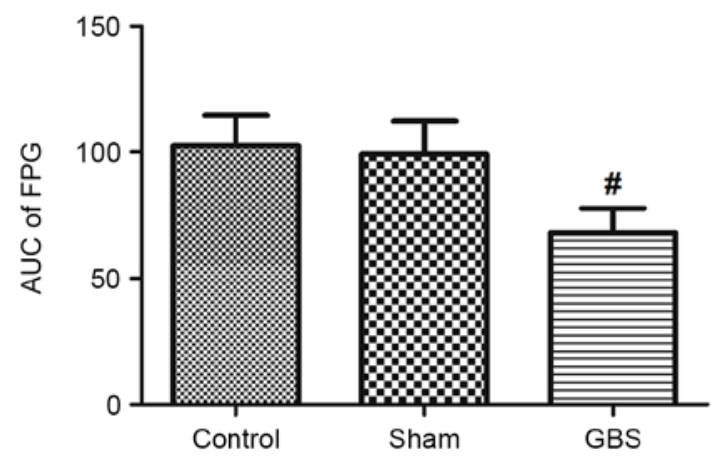

D

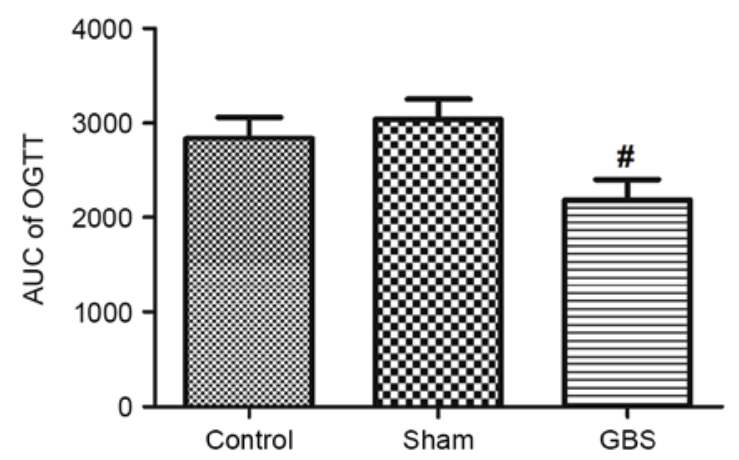

Figure 1. Effects of GPS on glycemic control in $\mathrm{db} / \mathrm{db}$ mice. (A) FPG in $\mathrm{db} / \mathrm{db}$ mice was evaluated weekly for two weeks prior to surgery as well as four weeks after surgery. Mice were fasted overnight and blood glucose levels were measured. (B) AUC of FPG. (C) The first week after GPS, OGTT were performed among Control, Sham and GBS groups. Mice were fasted overnight and then orally administered glucose ( $2 \mathrm{~g} / \mathrm{kg}$ body weight). Blood glucose levels were measured at the indicated time-points. (D) AUC of OGTT. ${ }^{\text {P }}<0.05$ vs. control group. FPG, fasting plasma glucose; AUC, area under curve; GBS, gastric bypass surgery; OGTT, oral glucose tolerance tests.

of the reaction products. GAPDH was used as an internal standard. The PCR primers used were as follows: Notch-1, sense GCTACAACTGCGTGTGTGTC and antisense GTT GGTGTCGCAGTTGGAGC; Notch-2, sense CACCTTGAA GCTGCAGACAT and antisense GGTAGACCAAGTCTG TGATG; Notch-3, sense ACTGGACCTCGCTGTGAGAC and antisense GCAGCTGAAGCCATTGACTC; Notch-4, sense GCTATGTGTCTCAGTGGTCA and antisense AAG CTTGGCCTGGCATCTCT; PDX-1, sense GGATGAAGT CTACCAAAGCTCACGC and antisense CCAGATCTTGAT GTGTCTCTCGGTC; Ngn3, sense CAATCGAATGCACAA CCTCA and antisense GGGAGACTGGGGAGTAGAGG; GAPDH, sense CACTGGCATGGCCTTCCGT and antisense, CTTACTCCTTGGAGGCCAT.

Statistical analysis. Values are expressed as the mean \pm standard error. Statistical analysis was performed with SPSS 17.0 software (SPSS, Inc., Chicago, IL, USA). Statistical analysis was performed using analysis of variance when appropriate, followed by an unpaired Student's t-test. $\mathrm{P}<0.05$ was considered to indicate a statistically significant difference.

\section{Results}

Effects of gastric bypass surgery on metabolic control in $\mathrm{db} / \mathrm{db}$ mice. The status of FPG in $\mathrm{db} / \mathrm{db}$ mice was evaluated weekly for two weeks prior to surgery as well as four weeks after surgery. The first two weeks prior to operation, FPG levels did not differ significantly between Control, Sham and GBS group, but FPG levels and the area under the curve (AUC) of FPG in the GBS group was significantly lower than that in the Control and Sham group at the first week after operation (Fig. 1A and B). The first week after operation, OGTTs were performed in the three groups. The blood glucose levels at time 0 did not differ significantly between Control, Sham and GBS groups; however, subsequent to surgery, the blood glucose levels in the GBS group were significantly lower than those in the Control and Sham group at different time-points, but elevated glucose levels in the GBS group at 10 min after the oral glucose gavage were gradually restored to original glucose levels at $120 \mathrm{~min}$ (Fig. 1C), indicating glucose intolerance remission after gastric bypass surgery. Simultaneously, in the GBS group, the AUC of glucose according to the OGTT was significantly declined 
A

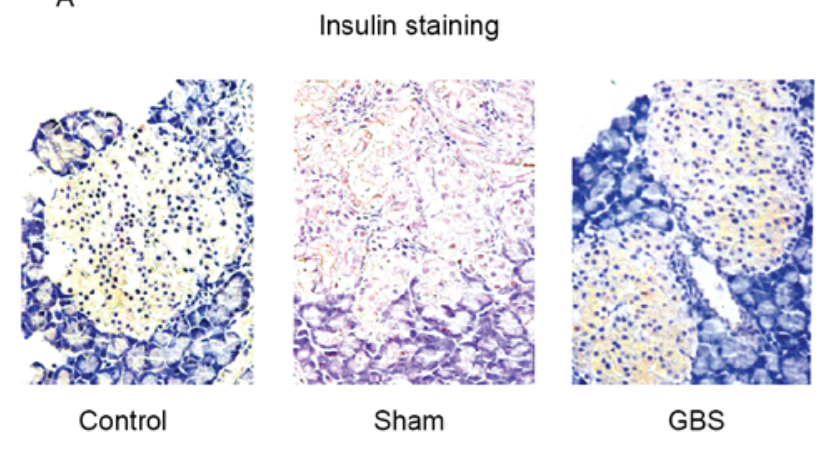

C

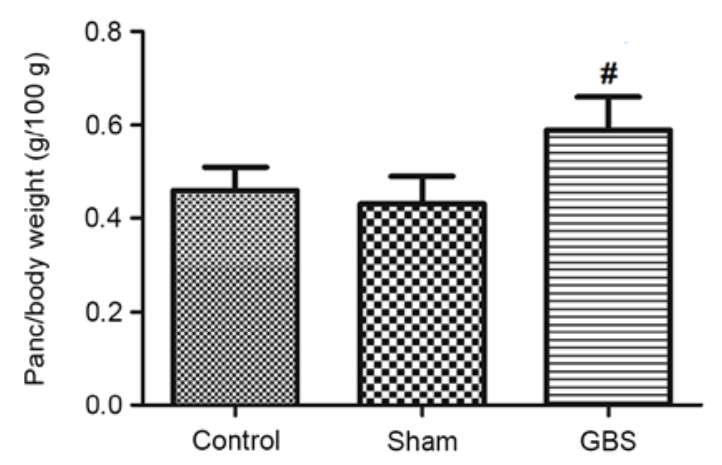

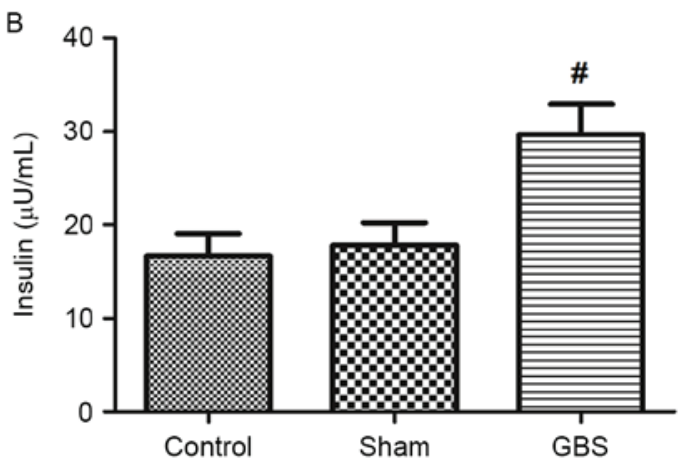

D

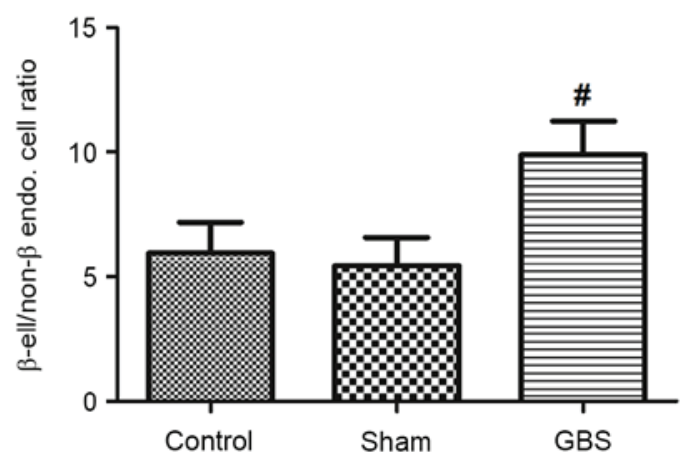

Figure 2. Pancreatic hyperplasia after gastric bypass surgery in db/db mice. (A) Representative microscopy/scanned immunohistochemistry images of islets in three groups stained with insulin (red brown, magnification $\mathrm{x} 400$ ). (B) Insulin secretion. (C) Pancreas weight expressed as g per $100 \mathrm{~g}$ body weight. (D) Ratio of insulin-positive $\beta$-cells to non- $\beta$ endocrine cells. ${ }^{\#} \mathrm{P}<0.05$ vs. control group. GBS, gastric bypass surgery; endo., endocrine.

compared with that in the Control and Sham group (Fig. 1D). These findings indicated that hyperglycemia and impaired glucose tolerance were improved in $\mathrm{db} / \mathrm{db}$ mice after gastric bypass surgery.

Effects of gastric bypass surgery on islet morphology and $\beta$-cell mass. Animals were sacrificed 4 weeks post-surgery. Pancreases were carefully excised, weighed and subjected to insulin immunohistochemical staining to observe any morphological changes. As shown in Fig. 2A, the islet structure in the Control and Sham groups was similar, as was islet cell histopathology: Reduced islets and increased interstitial fibrosis of islets, discrete distribution of $\beta$-cell mass due to the destruction of agglomerates formed, swelling deformation of a large amount of $\beta$-cells and damage on the formation of vacuoles were observed. In the GBS group, however, islet structure and histopathology were obviously improved: Abundant islets and reduced interstitial fibrosis of islets, a tight cell arrangement with massive $\beta$-cells in the central core as well as regeneration and hypertrophy of the $\beta$-cell mass were observed. In addition, Control and Sham group exhibited heterogeneous insulin staining relative to that in the GBS group, which was also weak. Meanwhile, insulin secretion in GBS group was significantly higher than that in the Control and Sham groups (Fig. 2B). Pancreas weight expressed as $\mathrm{g}$ per $100 \mathrm{~g}$ body weight was similar between Control and Sham groups, but was significantly higher in the GBS group (Fig. 2 C). Furthermore, the ratio of $\beta$-cells to non- $\beta$ endocrine cells did not differ significantly between Control and Sham groups, but was notably higher in the GBS group (Fig. 2D). These results suggested that gastric bypass surgery may promote pancreatic islet regeneration.

Effects of gastric bypass surgery on proteins involved in Notch signaling. Based on the known role of Notch signaling in regulating epithelial differentiation in pancreatic development, the levels of proteins involved in Notch signaling were detected among the three groups. As shown in Fig. 3A, compared with the Control and Sham groups, western blot analyses showed that the level of Notch-1 in the GBS group was conspicuously lower, but the levels of Notch-2, Notch-3 and Notch-4 did not obviously differ among the three groups. However, a marked increase in PDX-1 levels and a decrease in Ngn3 levels was observed in the GBS group. The RT-qPCR results further consolidated the results of the western blot analysis (Fig. 3B-G). All of these results indicated a potential role of Notch signaling in regulating pancreatic islet regeneration after gastric bypass surgery in $\mathrm{db} / \mathrm{db}$ mice.

Mechanism involved in pancreatic islet regeneration after gastric bypass surgery. To confirm the specific mechanism underlying the association between Notch signaling and pancreatic islet regeneration after gastric bypass surgery, the GBS group was divided into four groups: Control group, PDX-1 KO group, Notch-1 KO group and Ngn3 KO group. As shown in Fig. 4, Notch-1 or Ngn3 gene-deficient db/db mice did not exhibit any significant changes in the level of PDX-1. Notch-1 was significantly higher in the PDX-1 KO group, but was not 

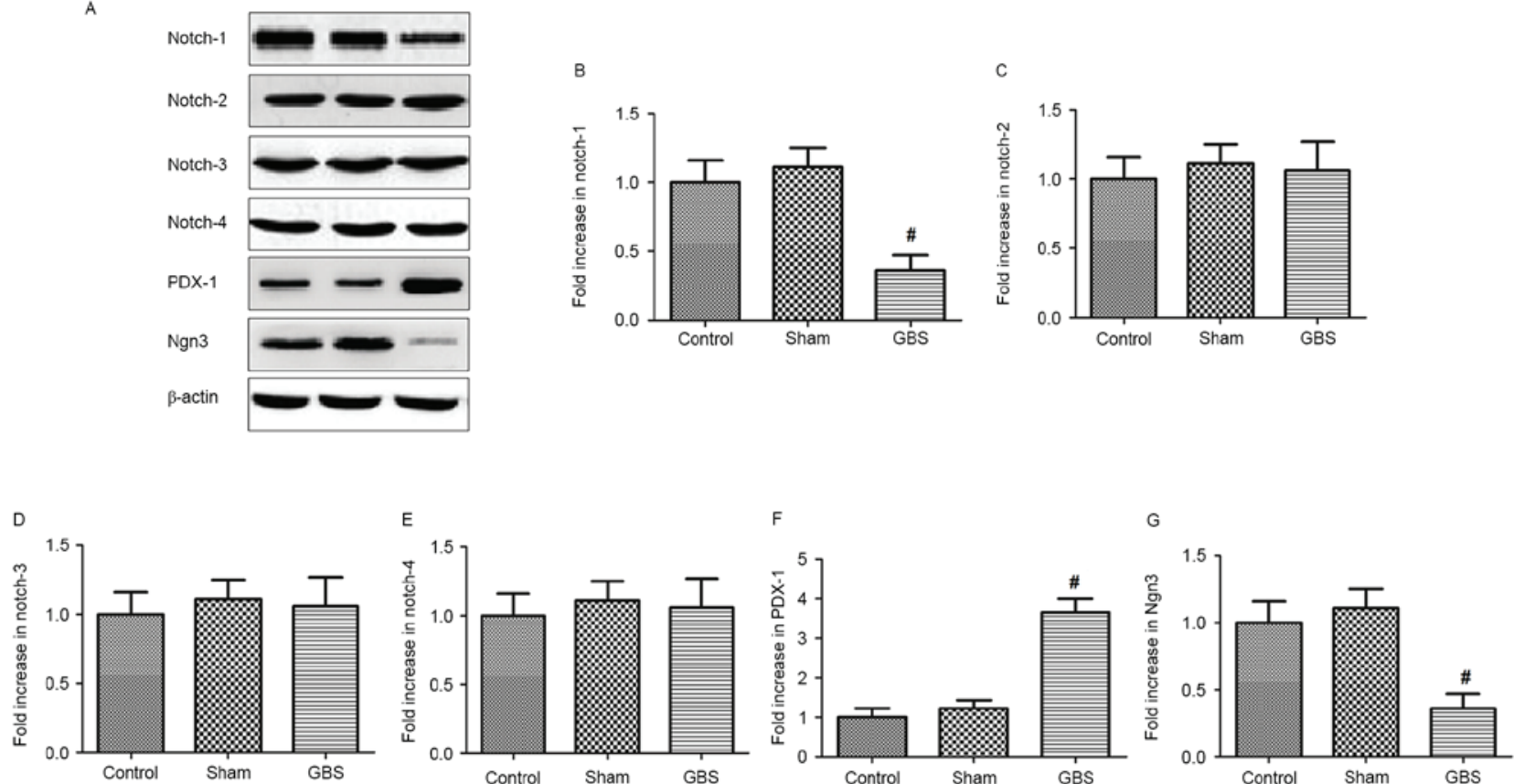

Figure 3. Levels of proteins involved in Notch signaling after gastric bypass surgery in db/db mice. (A) Levels of Notch1-4, PDX-1 and Ngn3 measured through western blotting in three groups. $\beta$-actin was used as a protein loading control. (B-G) Fold increase in (B) Notch-1, (C) Notch-2, (D) Notch-3, (E) Notch-4, (F) PDX-1 and (G) Ngn3 detected in the three groups through reverse-transcription quantitative polymerase chain reaction analysis. ${ }^{*} \mathrm{P}<0.05$ vs. control group. PDX-1, pancreatic and duodenal homeobox 1; Ngn3, neurogenin 3; GBS, gastric bypass surgery.

notably affected in the Ngn3 KO group. The PDX-1 KO group exhibited a significant decline in Ngn3, while it was obviously increased in the Notch-1 KO group. Considering that PDX-1 was significantly increased after gastric bypass surgery, it was hypothesized that elevated PDX-1 caused an inhibition of Notch-1 and further facilitated Ngn3, thus stimulating pancreatic $\beta$-cell regeneration after gastric bypass surgery. Therefore, the present study further investigated the influence of PDX-1/Notch-1/Ngn3 on pancreatic islets in the GBS group. As shown in Fig. 5A, insulin secretion was obviously decreased in the PDX-1 KO and Ngn3 KO groups, while being significantly elevated in the Notch-1 KO group. Similarly, a significant decrease in the $\beta$-cell to non- $\beta$ endocrine cell ratio was observed in the PDX-1 KO and Ngn3 KO groups, while the Notch-1 KO group showed a tremendous increase in the ratio of $\beta$-cell to non- $\beta$ endocrine cells (Fig. 5B). All of these results indicated that $\mathrm{PDX}-1 /$ Notch-1/Ngn3 signaling had a crucial role in regulating pancreatic islet regeneration in $\mathrm{db} / \mathrm{db}$ mice after gastric bypass surgery.

\section{Discussion}

T2DM frequently occurs in insulin-resistant subjects with hyperglycemia. A major challenge in reversing the deteriorative glycemic control in T2DM is to improve the function of pancreatic islets and increase the $\beta$-cell mass to meet the requirement for insulin. Gastric bypass surgery has been reported to be effective in reversing T2DM or preventing disease progression, resulting in a marked amelioration of diabetes in numerous morbidly obese patients $(26,27)$. Therefore, in the present study, FPG, glucose tolerance, insulin secretion, morphological changes in pancreatic islets as well as the underlying mechanisms were assessed in $\mathrm{db} / \mathrm{db}$ mice after gastric bypass surgery. The results revealed that gastric bypass surgery led to significant improvements in hyperglycemia and impaired glucose tolerance in $\mathrm{db} / \mathrm{db}$ mice, which was consistent with the results of earlier studies $(28,29)$, indicating the recovery of degenerative glycemic control capacity after surgery. In addition, a significant decrease in the AUC of FPG and OGTT results were observed in the present study.

Previous studies have reported the associations between intestine and pancreas. Haegel et al (30) observed exocrine pancreas hyperplasia in experimental rats following massive resection of the small intestine. Numerous studies have addressed the beneficial effect of gastrointestinal hormones on glycemic control after gastric bypass surgery in diabetic patients (31-33), particularly glucagon-like peptide-1 (GLP-1). Elevated GLP-1 markedly enhanced insulin secretion and also improved the function of pancreatic $\beta$-cells, thus ameliorating hyperglycemia after gastric bypass surgery in diabetic subjects $(34,35)$. GLP-1 is presumably associated with pancreatic $\beta$-cell neogenesis (36). As expected, in the present study, elevated insulin levels were observed in $\mathrm{db} / \mathrm{db}$ mice following gastric bypass surgery, which may have resulted from an increased $\beta$-cell mass and significant improvement in the structure of islets observed through insulin immunohistochemical staining. An increased $\beta$-cell area has been reported in rat models following a different type of bariatric surgery (37), as well as increased $\beta$-cell mass in porcine models (38). In the present study, the ratio of $\beta$-cells to non- $\beta$ endocrine cells was elevated after gastric bypass surgery, suggesting an increase in $\beta$-cells after surgery. In addition, pancreatic hyperplasia was observed in parallel with increased pancreas weight following surgery.

Further elucidation of the specific mechanism responsible for gastric bypass surgery-induced islet regeneration will 
A
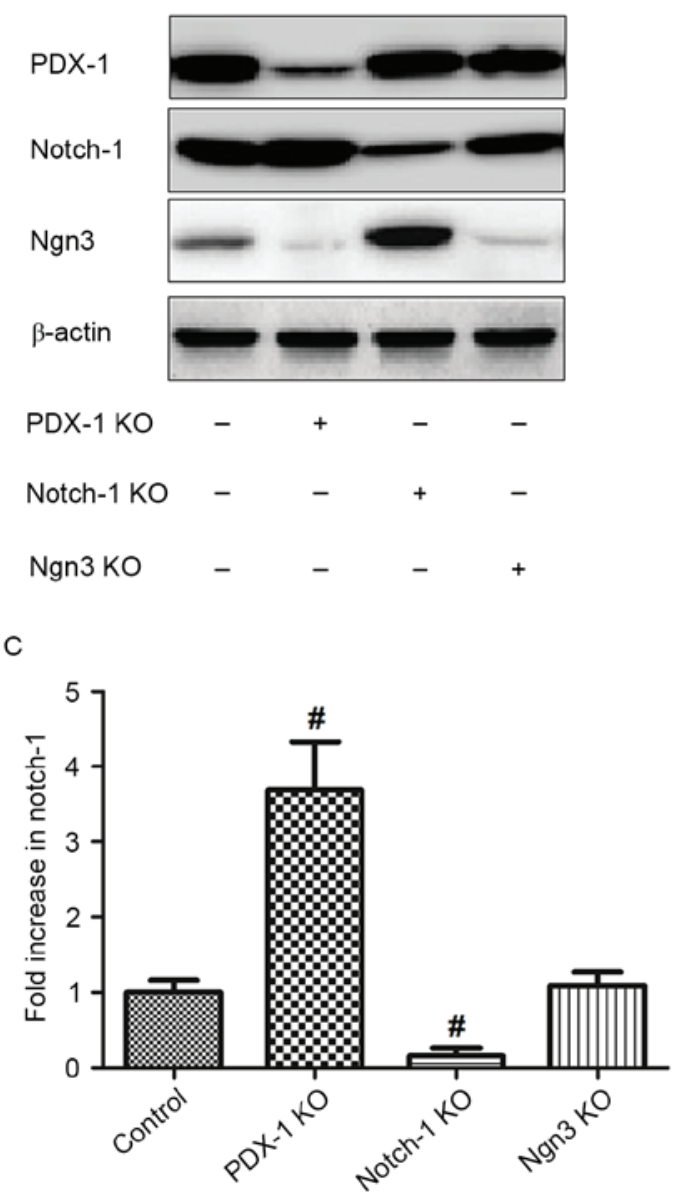

B

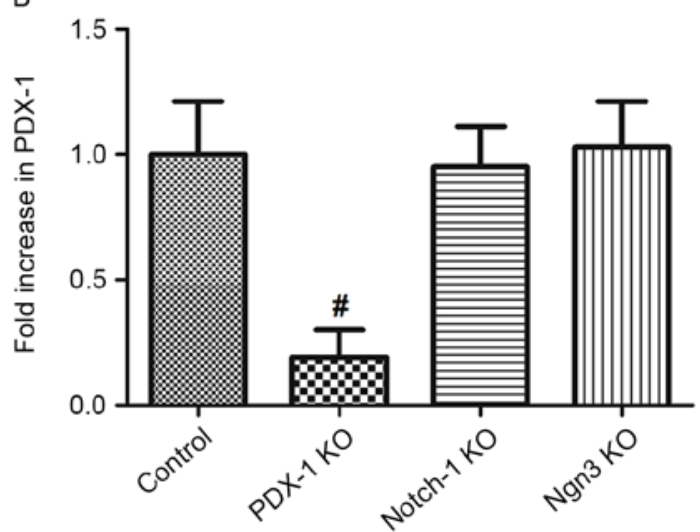

D

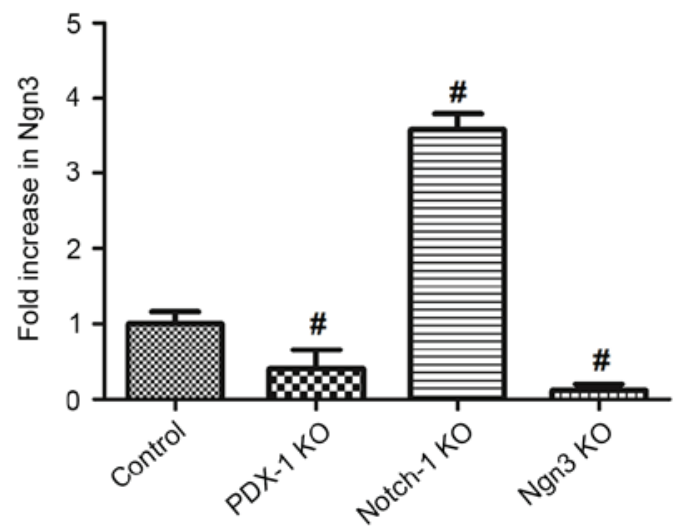

Figure 4. Potential mechanism involved in pancreatic islet regeneration after gastric bypass surgery in db/db mice. The GBS group was sub-divided into four groups: Control group, PDX-1 KO group, Notch-1 KO group and Ngn3 KO group. (A) Levels of Notch-1, PDX-1 and Ngn3 in the four groups. The levels of PDX-1, Notch-1, and Ngn3 were measured by western blot analysis. $\beta$-actin was used as a protein loading control. (B-D) Fold increase in (B) PDX-1, (C) Notch-1 and (D) Ngn3 measured in the four groups using reverse-transcription quantitative polymerase chain reaction analysis. ${ }^{~} \mathrm{P}<0.05$ vs. control group. PDX-1, pancreatic and duodenal homeobox 1; Ngn3, neurogenin 3; GBS, gastric bypass surgery; KO, knockout.

A

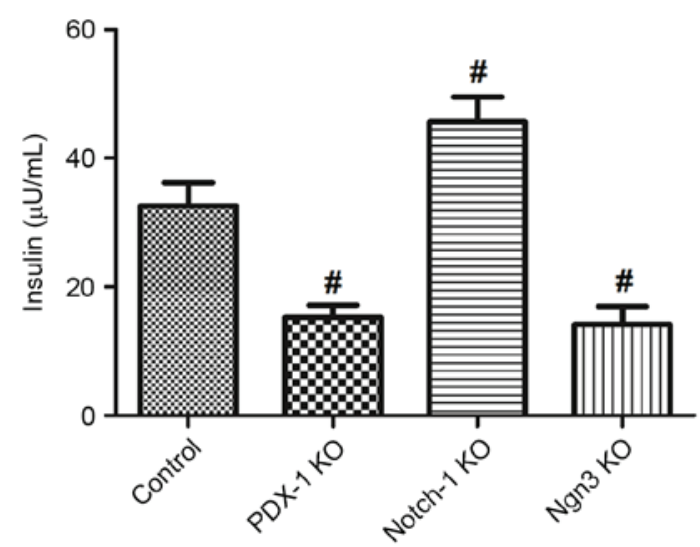

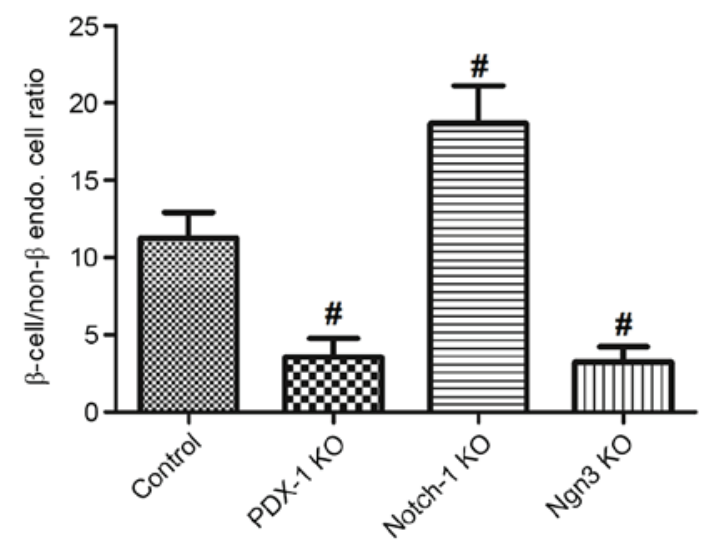

Figure 5. Influence of PDX-1/Notch-1/Ngn3 signaling on pancreatic islets in the GBS group. The GBS group was divided into four groups: Control group; PDX-1 KO group, Notch-1 KO group and Ngn3 KO group. (A) Insulin secretion in the four groups. (B) The ratio of $\beta$-cell to non- $\beta$ endocrine cell in the four groups. "P<0.05 control group. PDX-1, pancreatic and duodenal homeobox 1; Ngn3, neurogenin 3; GBS, gastric bypass surgery; KO, knockout.

largely enhance the current understanding of T2DM pathogenesis and facilitate the development of T2DM therapy. The current knowledge on pancreatic development suggests a potential role of Notch signaling in pancreatic hyperplasia. Notch was first reported in 1917, and subsequently, Notch-1, $-2,-3$ and -4 were found in vertebrates (39), among which 
Notch-1 exerted a pre-dominant effect on pancreatic embryonic development (40). In addition, pancreatic development may be regulated by PDX-1, which is expressed in pancreatic progenitor cells (41). It has been shown that the activation of Notch-1 prevented exocrine and endocrine differentiation of pancreatic progenitor cells, leaving a large amount of pancreatic epithelial cells in the neonatal stage, an undifferentiated state with PDX-1 being expressed (17). Ngn3 is recognized as a master regulator of pancreatic endocrine formation and Notch signaling as an important negative regulator of Ngn3 gene expression (42). Studies also suggested a link between $\mathrm{Ngn} 3$ and Notch signaling in pancreatic embryonic development. In a study by $\mathrm{Qu}$ et al (43), elevated Notch/Hes1 signaling was reported to inhibit Ngn3, subsequently negatively affecting endocrine differentiation. The Notch signaling target Hes1 appears to have a crucial role in this process, as it directly binds and represses Ngn3. In the present study, notable changes in the levels of PDX-1, Notch-1 and $\mathrm{Ngn} 3$ were observed in $\mathrm{db} / \mathrm{db}$ mice following gastric bypass surgery. Furthermore, the findings obtained with PDX-1 KO, Notch-1 KO and Ngn3 KO db/db mouse models with gastric bypass surgery suggested that the PDX-1/Notch-1/Ngn3 axis is involved in pancreatic islet regeneration after surgery, as elevated PDX-1 due to gastric bypass surgery produced the inhibition of Notch-1 and further facilitated Ngn3. These findings demonstrated that gastric bypass surgery in $\mathrm{db} / \mathrm{db}$ mice produced pancreatic islet regeneration through PDX-1/Notch-1/Ngn3 signaling. The present study provided evidence for a novel mechanism by which diabetes remission is induced by pancreatic islet cell regeneration after gastric bypass surgery in $\mathrm{db} / \mathrm{db}$ mice.

\section{Acknowledgements}

This project was supported by Shanghai Xuhui District Medical Scientific Research project (no. SHXH201307).

\section{References}

1. Virally M, Blicklé JF, Girard J, Halimi S, Simon D and Guillausseau PJ: Type 2 diabetes mellitus: Epidemiology, pathophysiology, unmet needs and therapeutical perspectives. Diabetes Metab 33: 231-244, 2007.

2. Zhu H, Zhang X, Li MZ, Xie J and Yang XL: Prevalence of type2 diabetes and pre-diabetes among overweight or obese children in Tianjin, China. Diabet Med 30: 1457-1465, 2013.

3. Garb J, Welch G, Zagarins S, Kuhn J and Romanelli J: Bariatric surgery for the treatment of morbid obesity: A meta-analysis of weight loss outcomes for laparoscopic adjustable gastric banding and laparoscopic gastric bypass. Obes Surg 19: 1447-1455, 2009.

4. Pontiroli AE and Alberto M: Long-term prevention of mortality in morbid obesity through bariatric surgery. A systematic review and meta-analysis of trials performed with gastric banding and gastric bypass. Ann Surg 253: 484-487, 2011.

5. Suteu I and Bucur AI: Surgical treatment of morbid obesity. I. Rev Chir Oncol Radiol O R L Oftalmol Stomatol Chir 32: 97-106, 1983 (In Romanian).

6. Schauer PR, Bartolome B, Ikramuddin S, Cottam D, Gourash W, Hamad G, Eid GM, Mattar S, Ramanathan R, Barinas-Mitchel E, et al: Effect of laparoscopic Roux-en-Y gastric bypass on type 2 diabetes mellitus. Ann Surg 238: 467-485, 2003.

7. Hall TC, Pellen MG, Sedman PC and Jain PK: Preoperative factors predicting remission of type 2 diabetes mellitus after Roux-en-Y gastric bypass surgery for obesity. Obes Surg 20: $1245-1250,2010$.
8. Kadera BE, Lum K, Grant J, Pryor AD, Portenier DD and Demaria EJ: Remission of type 2 diabetes after Roux-en-Y gastric bypass is associated with greater weight loss. Surg Obes Relat Dis 5: 305-309, 2009.

9. Rubino F, Zizzari P, Tomasetto C, Bluet-Pajot MT, Forgione A, Vix M, Grouselle D and Marescaux J: The role of the small bowel in the regulation of circulating ghrelin levels and food intake in the obese Zucker rat. Endocrinology 146: 1745-1751, 2005.

10. Liu Y,Zhou Y, Wang Y, Geng D and Liu J: Roux-en-Y gastric bypassinduced improvement of glucose tolerance and insulin resistance in type 2 diabetic rats are mediated by glucagon-like peptide-1. Obes Surg 21: 1424-1431, 2011

11. Papapietro K, Díaz E, Csendes A, Díaz JC, Braghetto I, Burdiles P, Maluenda F and Rojas J: Effects of gastric bypass on weight, blood glucose, serum lipid levels and arterial blood pressure in obese patients. Rev Med Chil 133: 511-516, 2005 (In Spanish).

12. Li Z, Zhang HY, Lv LX, Li DF, Dai JX, Sha O, Li WQ, Bai Y and Yuan L: Roux-en-Y gastric bypass promotes expression of PDX-1 and regeneration of beta-cells in Goto-Kakizaki rats. World J Gastroenterol 16: 2244-2251, 2010.

13. Hald J, Hjorth JP, German MS, Madsen OD, Serup P and Jensen J: Activated Notch1 prevents differentiation of pancreatic acinar cells and attenuate endocrine development. Dev Biol 260: 426-437, 2003.

14. Murtaugh LC, Stanger BZ, Kwan KM and Melton DA: Notch signaling controls multiple steps of pancreatic differentiation. Proc Natl Acad Sci USA 100: 14920-14925, 2003.

15. Fujikura J,Hosoda K, IwakuraH,Tomita T,Noguchi M, MasuzakiH, Tanigaki K, Yabe D, Honjo T and Nakao K: Notch/Rbp-j signaling prevents premature endocrine and ductal cell differentiation in the pancreas. Cell Metab 3: 59-65, 2006.

16. Su Y, Büchler P, Gazdhar A, Giese N, Reber HA, Hines OJ, Giese T, Büchler MW and Friess H: Pancreatic regeneration in chronic pancreatitis requires activation of the notch signaling pathway. J Gastrointest Surg 10: 1230-1242, 2006.

17. Siveke JT, Lubeseder-Martellato C, Lee M, Mazur PK, Nakhai H, Radtke F and Schmid RM: Notch signaling is required for exocrine regeneration after acute pancreatitis. Gastroenterology 134: $544-555,2008$

18. Miyamoto Y, Maitra A, Ghosh B, Zechner U, Argani P, Iacobuzio-Donahue CA, Sriuranpong V, Iso T, Meszoely IM, Wolfe MS, et al: Notch mediates TGF alpha-induced changes in epithelial differentiation during pancreatic tumorigenesis. Cancer Cell 3: 565-576, 2003.

19. Fukuda M, Nakamura T, Kataoka K, Nako H, Tokutomi Y, Dong YF, Yasuda O, Ogawa H and Kim-Mitsuyama S: Ezetimibe ameliorates cardiovascular complications and hepatic steatosis in obese and type 2 diabetic $\mathrm{db} / \mathrm{db}$ mice. J Pharmacol Exp Ther 335: 70-75, 2010

20. Nagashima T, Shigematsu N, Maruki R, Urano Y, Tanaka H, Shimaya A, Shimokawa T and Shibasaki M: Discovery of novel forkhead box $\mathrm{O} 1$ inhibitors for treating type 2 diabetes: Improvement of fasting glycemia in diabetic $\mathrm{db} / \mathrm{db}$ mice. Mol Pharmacol 78: 961-970, 2010

21. Wang H, Chen F, Zhong KL, Tang SS, Hu M, Long Y, Miao MX, Liao JM, Sun HB and Hong H: PPAR $\gamma$ agonists regulate bidirectional transport of amyloid- $\beta$ across the blood-brain barrier and hippocampus plasticity in db/db mice. Br J Pharmacol 173: 372-385, 2016.

22. Zhang R, Yan C, Zhou X, Qian B, Li F, Sun Y, Shi C, Li B, Saito S, Horimoto K and Zhou H: Association of Rev-erb $\alpha$ in adipose tissues with Type 2 diabetes mellitus amelioration after gastric bypass surgery in Goto-Kakizaki rats. Am J Physiol Regul Integr Comp Physiol 305: R134-R146, 2013.

23. Yamabe N,Kang KS and Zhu BT: Beneficial effect of $17 \beta$-estradiol on hyperglycemia and islet $\beta$-cell functions in a streptozotocin-induced diabetic rat model. Toxicol Appl Pharmacol 249: 76-85, 2010.

24. Kim JE, Lee MH, Nam DH, Song HK, Kang YS, Lee JE, Kim HW,

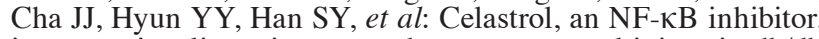
improves insulin resistance and attenuates renal injury in $\mathrm{db} / \mathrm{db}$ mice. PLoS One 8: e62068, 2013.

25. Matsubara J, Yamada Y, Nakajima TE, Kato K, Hamaguchi T, Shirao K, Shimada Y and Shimoda T: Clinical significance of insulin-like growth factor type 1 receptor and epidermal growth factor receptor in patients with advanced gastric cancer. Oncology 74: 76-83, 2008.

26. Khoo CM, Muehlbauer MJ, Stevens RD, Pamuklar Z, Chen J, Newgard CB and Torquati A: Postprandial metabolite profiles reveal differential nutrient handling after bariatric surgery compared with matched caloric restriction. Ann Surg 259: 687-693, 2014. 
27. Torquati A, Lutfi R, Abumrad N and Richards WO: Is Roux-en-Y gastric bypass surgery the most effective treatment for type 2 diabetes mellitus in morbidly obese patients? J Gastrointest Surg 9: 1112-1118, 2005.

28. Lin E, Liang Z, Frediani J, Davis SS Jr, Sweeney JF, Ziegler TR, Phillips LS and Gletsu-Miller N: Improvement in ß-cell function in patients with normal and hyperglycemia following Roux-en-Y gastric bypass surgery. Am J Physiol Endocrinol Metab 299: E706-E712, 2010.

29. Chai F, Wang Y, Zhou Y, Liu Y, Geng D and Liu J: Adiponectin downregulates hyperglycemia and reduces pancreatic islet apoptosis after roux-en-y gastric bypass surgery. Obes Surg 21 768-773, 2011.

30. Haegel P, Stock C, Marescaux J, Petit B and Grenier JF: Hyperplasia of the exocrine pancreas after small bowel resection in the rat. Gut 22: 207-212, 1981.

31. Romero F, Nicolau J, Flores L, Casamitjana R, Ibarzabal A Lacy A and Vidal J: Comparable early changes in gastrointestinal hormones after sleeve gastrectomy and Roux-En-Y gastric bypass surgery for morbidly obese type 2 diabetic subjects. Surg Endosc 26: 2231-2239, 2012.

32. Eickhoff H, Louro TM, Matafome PN, Vasconcelos F, Seiça RM and Castro E Sousa F: Amelioration of glycemic control by sleeve gastrectomy and gastric bypass in a lean animal model of type 2 diabetes: Restoration of gut hormone profile. Obes Surg 25: 7-18, 2015.

33. Jacobsen SH, Olesen SC, Dirksen C, Jørgensen NB, Bojsen-Møller KN, Kielgast U, Worm D, Almdal T, Naver LS, Hvolris LE, et al: Changes in gastrointestinal hormone responses, insulin sensitivity, and beta-cell function within 2 weeks after gastric bypass in non-diabetic subjects. Obes Surg 22: 1084-1096, 2012.

34. Morínigo R, Lacy AM, Casamitjana R, Delgado S, Gomis R and Vidal J: GLP-1 and changes in glucose tolerance following gastric bypass surgery in morbidly obese subjects. Obes Surg 16: 1594-1601, 2006.
35. Laferrere B, Tran HC, Yap KP, Heshka S, McGinty J, Teixeira J and Olivan B: GLP-1 and GIP levels and effect are markedly enhanced one month after roux-en-y gastric bypass surgery in obese patients with type 2 diabetes. Diabetes 56: 374-375, 2007.

36. Xu G, Kaneto H, Lopez-Avalos MD, Weir GC and Bonner-Weir S: GLP-1/exendin-4 facilitates beta-cell neogenesis in rat and human pancreatic ducts. Diabetes Res Clin Pract 73: 107-110, 2006.

37. Speck M, Cho YM, Asadi A, Rubino F and Kieffer TJ: Duodenal-jejunal bypass protects GK rats from \{beta\}-cell loss and aggravation of hyperglycemia and increases enteroendocrine cells coexpressing GIP and GLP-1. Am J Physiol Endocrinol Metab 300: E923-E932, 2011.

38. Lindqvist A, Spégel P, Ekelund M, Garcia Vaz E, Pierzynowski S, Gomez MF, Mulder H, Hedenbro J, Groop L and Wierup N: Gastric bypass improves $\beta$-cell function and increases $\beta$-cell mass in a porcine model. Diabetes 63: 1665-1671, 2014.

39. Gittes GK: Developmental biology of the pancreas: A comprehensive review. Dev Biol 326: 4-35, 2009.

40. Nakhai H, Siveke JT, Klein B, Mendoza-Torres L, Mazur PK, Algül H, Radtke F, Strobl L, Zimber-Strobl U and Schmid RM: Conditional ablation of Notch signaling in pancreatic development. Development 135: 2757-2765, 2008.

41. Svensson P, Williams C, Lundeberg J, Rydén P, Bergqvist I and Edlund $\mathrm{H}$ : Gene array identification of Ipf $1 / \mathrm{Pdx} 1-/-$ regulated genes in pancreatic progenitor cells. BMC Dev Biol 7: 129, 2007.

42. Shih HP, Kopp JL, Sandhu M, Dubois CL, Seymour PA, Grapin-Botton A and Sander M: A Notch-dependent molecular circuitry initiates pancreatic endocrine and ductal cell differentiation. Development 139: 2488-2499, 2012.

43. Qu X, Afelik S, Jensen JN, Bukys MA, Kobberup S, Schmerr M Xiao F, Nyeng P, Veronica Albertoni M, Grapin-Botton A and Jensen J: Notch-mediated post-translational control of Ngn3 protein stability regulates pancreatic patterning and cell fate commitment. Dev Biol 376: 1-12, 2013. 